\title{
Prognosis in pregnant women with systemic lupus erythematosus following pregnancy management.
}

\author{
En-Ling Liu ${ }^{1}$, Zheng $\mathrm{Liu}^{2}$, Bao-Feng Han ${ }^{3}$, Hong-Xiu Ma ${ }^{3}$, Shuai-Shuai $\mathrm{Li}^{3}$ and Yu-Xiu Zhou ${ }^{3}$ \\ ${ }^{1}$ Department of Obstetries and Gynecology, Tangshan Gongren Hospital, Hebei Medical \\ University, Tangshan. China. \\ ${ }^{2}$ Rheumatism Immunity Branch, Tianjin Medical University General Hospital, Tianjin. \\ China. \\ ${ }^{3}$ Rheumatism Immunity Branch, Tangshan Gongren Hospital, Hebei Medical University, \\ Tangshan. China.
}

Key words: Systemic lupus erythematosus; pregnancy management; maternal and neonatal outcome; autoantibody to nuclear antigen; low immunoglobulin complement; preǵnancy induced hypertension.

\begin{abstract}
This study was aimed to understand the effects of pregnancy management in the prognosis for pregnant women with systemic lupus erythematosus (SLE). A total of 217 pregnant patients who were diagnosed with SLE were divided into two groups, the control group $(n=96)$ and the intervention group $(n=121)$. The intervention group was treated with routine treatment and nursing care with additional pregnancy management, while the control group was treated with only routine treatment and nursing care. Additionally, 195 normal pregnant women were selected as the healthy controls in the same period. No significant difference of clinical features was observed in the three groups. Compared with the healthy control, increased ANA titer and dsDNA, lower immunoglobulin complement, renal damage, blood system damage, increased SLEDAI score and BILAG score were observed in the control group and the invention group. Both the control group and the intervention group showed significant increases in the incidences of PIH, premature delivery, fetal loss and neonatal complications as well as a significant decrease in neonatal weight compared with the healthy control. SLE activity rate and incidences of PIH, premature delivery and neonatal complications were significantly decreased; while neonatal weight was greatly increased in the intervention group compared with the control group. Low immunoglobulin complement, renal damage, increased dsDNA, and low immunoglobulin complement were independent risk factors for increased SLE activity rate, fetal loss, premature delivery and neonatal complications, respectively. The present study indicates that pregnancy management for pregnant SLE patients could significantly improve maternal and neonatal outcomes.
\end{abstract}

Corresponding author: Yu-Xiu Zhou, Rheumatism Immunity Branch, Tangshan Gongren Hospital, Hebei Medical University, No. 27, Wenhua Road, Tangshan 063000, Hebei Province, P.R. China. Tel: +86-0315-2395279. E-mail: 1f93ci@163.com 


\title{
El pronóstico en las mujeres embarazadas con lupus eritematoso sistémico tras el manejo del embarazo.
}

\author{
Invest Clin 2018; 59 (4): 293 - 301
}

Palabras clave: Lupus eritematoso sistémico; embarazo; gestión de los resultados

maternos y neonatales; autoanticuerpo antigeno nuclear de inmunoglobulina

A, bajos complemento; hipertensión inducida por el embarazo.

Resumen. Este estudio tuvo como objetivo comprender los efectos del manejo del embarazo en el pronóstico para embarazadas con lupus eritematoso sistémico (SLE). Se estudiaron 217 embarazadas con diaǵnóstico de SLE divididas en dos grupos, control $(n=96)$ y de intervención $(n=121)$. El grupo de intervención recibió tratamiento de rutina y de enfermería con manejo del embarazo, mientras que el otro grupo solo tratamiento de rutina y de enfermería. Además, 195 embarazadas normales fueron seleccionadas como grupo control sano. Se observó mayor titulación ANA y dsDNA, menor complemento de inmunoǵlobulinas, daño renal, daño del sistema arterial, aumento de la cuenta de SLEDAI y el índice BILAG en el grupo control y el de intervención, en comparación con el control sano. El grupo control y de intervención mostraron un aumento significativo en la incidencia de preeclampsia, parto prematuro, pérdida fetal y neonatal, y disminución significativa de peso neonatal en comparación con el control sano. La tasa de actividad SLE y la incidencia de preeclampsia, parto prematuro y las complicaciones neonatales se redujeron significativamente, mientras que el peso neonatal aumentó considerablemente en el grupo de intervención, en comparación con el control. Los resultados del análisis de regresión logistica mostraron que el complemento de inmunoǵlobulina bajo, daño renal, aumento de inmunoǵlobulinas y complemento bajo dsDNA, fueron factores de riesgo independientes para el aumento de la tasa de actividad de SLE, pérdida fetal, parto prematuro y complicaciones neonatales, respectivamente. El presente estudio sugiere que el manejo del embarazo en pacientes con SLE podría mejorar significativamente los resultados maternos y neonatales.

Recibido 06-03-2018 Aceptado 27-09-2018

\section{INTRODUCTION}

Systemic lupus erythematosus (SLE) is a serious multi-system disease affecting various organs, predominantly in women of childbearing age (female: male ratio approximately 9:1) $(1,2)$. Generally, SLE is believed to have a correlation with heredity and the environmental factors particularly include ultraviolet light exposure and estro- gen levels (3). The high estrogen levels are a major cause of SLE activity because the rising estrogen levels enhances the prolactin levels, which result in increasing immune response even disorder. At the same time, pregnancy will aggravate the burden on heart and kidney in order to induce SLE activity (4). Pregnancy with SLE is considered as a kind of high risk pregnancy, because SLE activity will be increased during preg- 
nancy which causes vital organs damage and subsequently affects fetus of patients (5). Moreover, the recurrence rate of SLE during pregnancy reached $13 \%$ to $68 \%$, which may lead to spontaneous abortion, premature birth, stillbirth, intrauterine growth retardation, premature rupture of membrane and neonatal lupus erythematosus (1). That means the recurrence rate of an SLE flare as SLE itself will not go away.

Currently, the treatment of SLE is mainly based on cortical hormone, and the -enhancement of medical technology - helps the continuous progress in drug therapy and stem cell transplantation, so more and more SLE patients have reproduction requirements (6). Stem cell transplantation improves reproductive outcomes for women with SLE. Besides, one study has shown that the key for the reproduction of SLE patients is the timing of conception (7). However, routine treatment alone cannot completely meet the reproduction requirements of patients (6), and it is important to explore the pregnancy management in pregnant SLE patients for maternal and child prognosis. So the fertility levels of SLE patients could be improved via the timing of conception, corresponding routine treatment and pregnancy management (8). This study aimed to explore the effects of pregnancy management on the maternal and neonatal prognosis of pregnant SLE patients.

\section{MATERIALS AND METHODS}

\section{Ethics statement}

This study was performed with the approval of the clinical management committee in our hospital. All patients in this study have signed the informed consents. All procedures were strictly conducted in accordance with the Declaration of Helsinki involving human beings.

\section{Study subjects}

A total of 217 pregnant SLE patients (all selective pregnancy) who were admit- ted and diagnosed at the Department of Rheumatology in our hospital from January 2010 to November 2015 were recruited and divided into two groups, that is, the control group $(\mathrm{n}=96)$ and intervention group ( $\mathrm{n}$ $=121$ ), in which the control group only received routine treatment and nursing while intervention group had additional pregnancy management. Meanwhile, a total of 195 pregnant women in the same period were included as normal group. The women in the healthy normal group did not have any underlying immune disorders, such as rheumatoid arthritis and chronic hypertension. All cases in the control group and the intervention group were in accordance with the diagnostic criteria of SLE recommended by American College of Rheumatology (ACR) in 1997 (9). The women with SLE did not have any flares within the last six months prior to pregnancy and were not taking any medication for SLE prior to pregnancy. Except for tumor and connective tissue diseases, patients with four or more manifestations were diagnosed as SLE, including discoid erythema, cheekbone erythema, oral ulcer, photaesthesia, serositis, non-erosive arthritis, hematological abnormality, neural abnormality, immunological abnormality, renal lesion and positive antinuclear antibody. The systemic lupus erythematosus disease activity index (SLEDAI) was performed to classify clinical condition (10), that is, less than or equal to 4 points was regarded as non-active group, and greater than or equal to 5 points was regarded as active group. On the basis of lesion type, all patients were divided into skin lesion type, nephritis type, arthrosis type and non-positive immune antibody type. All SLE patients were voluntarily participated in this study, and the patients with other autoimmune diseases, infection and organ function failure were excluded.

Routine treatment and nursing method: prevention of cold and expectant treatment when having a fever; a good rest during SLE activity; avoiding of sunlight and high-light

Vol. 59(4): 293 - 301, 2018 
exposure; forbiddance of photosensitive drugs and food, and a diet of high protein, high vitamin, low sugar, low salt and low fat; calcium supplement and forbiddance of smoking, drinking and spicy food; observation of side effects upon using hormone and immunosuppressive agents.

Preǵnancy manaǵement: durinǵ preǵnancy, patients were monitored by the Department Gynecology and Obstetrics and the Department of Rheumatology via regular electrocardiogram, ultrasound and ultrasound echocardiography and routine obstetric fetal monitoring, including determining gestational age in early pregnancy, detecting fetal development by ultrasound in middle pregnancy to determine fetal malformation preliminarily, and the late detection of fetal movement and fetal heart so as to determine periodic detection time and therapy, namely, prednisone $5-10 \mathrm{~g}$ /day to maintain stable condition, and hydroxychloroquine sulfate $0.1-0.2 \mathrm{~g} /$ day was added to original therapy if necessary (adjust dose and therapy according to the disease condition). Before delivery, the intramuscular injection of dexamethasone $10 \mathrm{mg} /$ day was added for three days in order to promote the maturity of fetal lung. Three days after delivery, patients recovered to the original dose. Once patients had SLE activity or complications during detecting serological activity index, they need shock treatment with large doses of hormones even adding immunosuppressive agents, and if necessary, they also need blood transfusion, platelet transfusion and protein supplement. The indications for pregnancy termination should be considered on the basis of maternal and fetal conditions. When the mother had severe complications, the pregnancy should be terminated right now no matter how long the pregnancy was. As for patients who were found placentas aging with mature fetus, once they had fetal distress or obstetrical indication, the pregnancy should be terminated via caesarean section or vaginal delivery.

\section{Detection of disease index}

The laboratory conducted regular detections for all patients in each group, including autoantibody to nuclear antigen (ANA), double stranded-DNA (dsDNA) antibody, immunoglobulin complement $\mathrm{C}_{3}$, liver $\&$ kidney functions, blood routine examination, routine urine test and 24-hour urinary protein quantity, in order to statistically analyze the changes of related indexes in each group. SLEDAI and British Isles Lupus Assessment Group (BILAG) were performed to score SLE patients (11).

\section{Maternal and neonatal outcomes}

During the research, all clinical features and the maternal and fetus outcomes were collected. Besides, SLE activity rate, incidence of pregnancy induced hypertension (PIH), incidence of premature delivery, incidence of fetal loss, and neonatal birth weight were observed and recorded. Moreover, whether newborns had fetal growth restriction (FGR), neonatal lupus syndrome (NLS) and neonatal asphyxia were also observed so as to register the incidence of neonatal complications.

\section{Statistical analysis}

The statistical analysis was performed using SPSS 21.0 (SPSS Inc, Chicago, IL, USA) software. All measurement data were expressed as mean \pm standard deviation (SD), and $t$-test was used to compare the mean difference of continuous variable between two groups. Enumeration data were expressed as percentage or ratio, which were compared by $\mathrm{x}^{2}$ test, $p<0.05$ was considered statistically significant.

\section{RESULTS}

\section{Clinical feature of subjects among three groups}

The clinical features of all the subjects in three groups were recorded. In the normal group, the age was $28.6 \pm 5.2$ years old, the weight was $55.7 \pm 8.5 \mathrm{~kg}$, and the gravidity 
was $2.1 \pm 1.2$; in the control group, the age was $27.8 \pm 4.5$ years old, the weight was 56.6 $\pm 3.2 \mathrm{~kg}$, and the gravidity was $2.0 \pm 1.0$ in the intervention group, the age was 29.0 \pm 4.9 years old, the weight was $57.4 \pm 3.5$ $\mathrm{kg}$, and the gravidity was $1.8 \pm 1.5$. As shown in Table I, the analysis results showed that there were no significant differences in age, weight and gravidity among three groups (all $p>0.05$ ). Moreover, the analysis of clinical features including lesion type and disease condition type demonstrated no significant difference between the control group and the intervention group (all $p>0.05$ ).

\section{Comparisons of disease indexes in each group}

As shown in Table II, the comparison of disease indexes in each group revealed that there were no changes in related disease indexes in the normal group. While in the control group and the intervention group, the related disease indexes were changed, including increased ANA titer, increased dsDNA titer, low immunoǵlobulin complement, renal damage, and blood system damage, increased SLEDAI score and BILAG score. When compared with the control group, the rate of patients in the intervention group with changed disease indexes were significantly lower (all $p<0.05$ ).

\section{Comparisons of maternal and neonatal outcomes}

During the research, the analysis results about clinical features and the maternal and neonatal outcomes showed that, when compared with the normal group, patients in the control group and the intervention group had an obvious increase in the incidences of $\mathrm{PIH}$, premature delivery, fetal loss and neonatal complications, and an evident decrease in neonatal weight (all $p<0.05$ ). Compared with the control group, patients in the intervention group had an evident decrease in SLE activity rate and incidences of PIH, premature delivery and neonatal complications (all $p<0.05$ ), but a great increase in neonatal weight $(p<0.05)$. There was no significant difference in fetal loss between two groups $(p>0.05)$ (Table III).

TABLE I

BASIC CLINICAL INFORMATION FOR ALL PARTICIPANTS BEFORE TREATMENT

\begin{tabular}{lccc} 
& Intervention $\mathrm{n}=121$ & Control $\mathrm{n}=96$ & Healthy $\mathrm{n}=195$ \\
\hline Age, years* & $29.0 \pm 4.9$ & $27.8 \pm 4.5$ & $28.6 \pm 5.2$ \\
Weight, kg* & $57.4 \pm 3.5$ & $56.6 \pm 3.2$ & $55.7 \pm 8.5$ \\
Gravidity, month* & $1.8 \pm 1.5$ & $2.0 \pm 1.0$ & $2.1 \pm 1.2$ \\
SLEDAI ** & & & \\
$\quad \leq 4$ & $73(60.3)$ & $61(63.5)$ & \\
$\quad \geq 5$ & $48(39.7)$ & $35(36.5)$ & \\
Lesion type ** & & & \\
$\quad$ Skin lesion type & $48(39.7)$ & $37(38.5)$ & \\
$\quad$ Nephritis type & $34(28.1)$ & $28(28.2)$ & \\
$\quad$ Arthrosis type & $29(24.0)$ & $24(25)$ & \\
$\quad$ Non-positive immune antibody type & $10(8.3)$ & $7(7.3)$ & \\
\hline
\end{tabular}

SLEDAI, Systemic lupus erythematosus disease activity index before treatment.

$*(\mathrm{x} \pm \mathrm{SD}) . \quad * \mathrm{n}(\%)$

Vol. 59(4): 293 - 301, 2018 
TABLE II

COMPARISONS OF DISEASE INDEXES IN EACH GROUP

\begin{tabular}{|c|c|c|c|c|c|c|c|}
\hline & $\begin{array}{c}\text { ANA } \\
\text { positive, } \\
\mathrm{n}(\%)\end{array}$ & $\begin{array}{c}\text { dsDNA } \\
\text { positive, } \\
\text { n (\%) }\end{array}$ & $\begin{array}{c}\text { Immunoglobulin } \\
\text { complement } \mathrm{C} 3 \text {, } \\
\mathrm{g} / \mathrm{L}\end{array}$ & $\begin{array}{c}24 \mathrm{~h} \\
\text { Proteinuria, } \\
\text { positive, } \\
\text { n (\%) }\end{array}$ & $\begin{array}{c}\text { Thrombo- } \\
\text { cytopenia, } \\
\text { n (\%) }\end{array}$ & SLEDAI & BILAG \\
\hline $\begin{array}{c}\text { Healthy, } \\
n=195\end{array}$ & $13(6.7)$ & $2(1.0)$ & $1.39 \pm 0.41$ & $0(0)$ & $0(0)$ & & \\
\hline $\begin{array}{c}\text { Intervention, } \\
\mathrm{n}=121\end{array}$ & $91(75.2)$ & $83(68.6)$ & $1.01 \pm 0.36$ & $81(66.9)$ & $17(14.0)$ & $4.2 \pm 1.1$ & $4.6 \pm 1.2$ \\
\hline $\begin{array}{c}\text { Control, } \\
\mathrm{n}=96\end{array}$ & $93(96.9)$ & $81(84.4)$ & $0.75 \pm 0.24$ & $79(82.3)$ & $25(26.0)$ & $5.1 \pm 1.3$ & $5.9 \pm 1.6$ \\
\hline
\end{tabular}

SLEDAI, systemic lupus erythematosus disease activity index; BILAG, British Isles Lupus Assessment Group.

TABLE III

COMPARISONS OF DISEASE INDEXES IN EACH GROUP

\begin{tabular}{lccc}
\hline & Intervention $\mathrm{n}=121$ & Control $\mathrm{n}=96$ & Healthy $\mathrm{n}=195$ \\
Pregnancy induced hypertension. & $15(12.4)$ & $23(24.0)$ & $8(4.1)$ \\
\hline Premature delivery, n (\%) & $25(20.7)$ & $34(35.4)$ & $15(7.7)$ \\
Fetal loss, n (\%) & $22(18.2)$ & $21(24.0)$ & $1(0.5)$ \\
Complications of live birth (n \%) & & & $3(1.5)$ \\
$\quad$ Fetal distress & $13(13.1)$ & $19(25.3)$ & $2(1.0)$ \\
Neonatal asphyxia & $5(5.1)$ & $10(13.3)$ & \\
SLE activity rate & $44(36.4)$ & $56(58.3)$ & $3.2 \pm 1.4$ \\
Neonatal weight, kg (x \pm SD) & $2.5 \pm 1.1$ & $2.1 \pm 1.2$ & \\
\hline
\end{tabular}

Analysis of disease indexes related to the adverse maternal and neonatal outcomes

The data in the control group and the intervention group were combined to analyze the disease indexes that affecting the adverse maternal and neonatal outcomes. The univariate analysis revealed that the adverse maternal and neonatal outcomes were correlated with the increased ANA titer and dsDNA titer, low immunoglobulin complement, renal damage, and blood system damage as well as increased SLEDAI score and BILAG score (all $p<0.05$ ). With the adverse maternal and neonatal outcomes as dependent variable and with the disease indexes showing significant differences by univariate analysis as independent variables to conduct the logistic analysis. The results showed that low immunoglobulin complement, renal damage, increased dsDNA titer, increased dsDNA titer were independent risk factors for adverse maternal and neonatal outcomes (all $p<0.05$ ) (Table IV).

\section{DISCUSSION}

SLE is a common chronic autoimmune disease affecting multiple organs with complicated clinical manifestations, which was once an important pregnancy contraindication $(12,13)$. Moreover, when combined with normal pregnant women, the pregnant 


\section{TABLE IV}

RISK FACTORS ASSOCIATED WITH ADVERSE MATERNAL AND NEONATAL OUTCOMES BY LOGISTIC MULTIVARIATE REGRESSION ANALYSIS

\begin{tabular}{lcccc}
\hline & Wald & Odds ratio & $95 \%$ CI & $p$ value \\
\hline ANA titer & 3.125 & 1.234 & $(0.259 \sim 2.386)$ & 0.016 \\
dsDNA titer & 2.456 & 1.056 & $(0.312 \sim 2.469)$ & 0.023 \\
Immunoglobulin complement $\mathrm{C}_{3}$ & 2.689 & 2.335 & $(1.735 \sim 6.427)$ & 0.008 \\
Renal damage & 5.247 & 3.126 & $(2.134 \sim 6.213)$ & 0.005 \\
Blood system damage & 3.165 & 1.036 & $(0.572 \sim 2.823)$ & 0.005 \\
SLEDAI & 7.613 & 5.164 & $(1.687 \sim 8.125)$ & 0.031 \\
BILAG & 6.524 & 3.134 & $(1.257 \sim 6.439)$ & 0.001 \\
\hline
\end{tabular}

SLE patients have a significant increase in obstetric complications such as spontaneous abortion, FGR, preeclampsia and intrauterine fetal death (14), which even causes nephropathy and PIH (15). This study aimed to explore the effects of pregnancy management on maternal and neonatal prognosis in pregnant SLE patients.

The results showed after routine treatment, pregnant SLE patients had a decrease in ANA titer and dsDNA titer, an increase in low immunoglobulin complement, a reduction in kidney and blood system damage and a decrease in SLEDAI score and BILAG score. Meanwhile, the proportion of deteriorated disease condition in patients who had pregnancy management was significantly decreased. During pregnancy, the immune response for women is mainly based on Th2 dominant immune response since Th1/Th2 response imbalance occurs, which results in high reactivity of $\mathrm{B}$ cells $(16,17)$. Here, $\mathrm{B}$ cells mediates the internal immune response, so the excessive activity of $\mathrm{B}$ cells, namely high reactivity of $\mathrm{B}$ cells, is a kind of abnormal immune response (18). Furthermore, the high reaction of $B$ cells in patients leads to abnormal immunological indexes involving complement levels, ANA titer, dsDNA titer and low immunoglobulin complement (19). During pregnancy management, prednisone was used to prevent the immune response caused by cellular immunity and to control SLE activity, which can prevent further deterioration of SLE (20), and later the proper monitor and treatment can effectively reduce the relevant conditions. Correspondingly, the levels of several risk factors, like internal complement and dsDNA antibody could be reduced via intervention treatments such as timing of conception and drug therapy so as to reduce the incidence of PIH (21).

Moreover, this study reported that after pregnancy management, pregnant SLE patients had a significant decrease in the incidence of SLE activity rate, PIH, premature delivery and neonatal complications and an evident increase in neonatal weight. The placenta sedimentation of immune complex and complement in serum in pregnant SLE patients leads to the damage of vascular endothelial cells and subsequently causes local microthrombus, thickened vessel wall and lumimal stenosis, which results in placental villi dysplasia, so their exchange function was affected, that is the nutrition supply to fetus was reduced, which finally gives rise to the higher incidences of recurrent spontaneous abortion, FGR, premature delivery, stillbirth and perinatal anoxia and ischemia (22). Besides, a previous study also reported that the effective pregnancy management can reduce the incidences of fetal loss and premature delivery (23). 
In addition, this study proved that low immunoglobulin complement, renal damage and dsDNA titer \& low immunoglobulin complement were independent risk factors for increased SLE activity rate, fetal loss and neonatal complications, respectively. SLE patients' pregnancies mainly bring damages to kidney and blood system, which accelerates the deterioration of renal function, while the damages to skin and skeletal muscle are relatively mild $(24,25)$. There is some impact of SLE on maternal and fetal outcomes following pregnancy, and differences in clinical features observed between childhood-onset versus adult-onset SLE (26, 27). Furthermore, spasm of uterus and relevant vessels caused by renal lesions leads to blood circulation disorder that blocks maternal and fetal blood exchange, resulting in fetal hypoxia even death, and especially the lupus nephritis will enlarge the risk of fetal loss (7). As dexamethasone has been shown to have conflicting reports on fetal outcome but some positive benefit on maternal immune suppression one might expect more maternal benefit depending on when in gestation this was administered. In this present study, the gestational age of women in the SLE intervention group administered dexamethasone were 30 to 38 weeks old.

To sum up, our study provides evidence that pregnancy management for pregnant SLE patients is able to significantly improve maternal and fetal outcomes. However, this study neither further explored the mechanism of pregnancy management for pregnant SLE patients, nor optimized the pregnancy management. Therefore, with limitations in the results, it is necessary to further explore the treatment and optimization of pregnancy management for pregnant SLE patients.

\section{REFERENCES}

1. Yan Yuen S, Krizova A, Ouimet JM, Pope JE. Pregnancy outcome in systemic lupus erythematosus (SLE) is improving: Results from a case control study and literature review. Open Rheumatol J 2008;2:89-98.

2. Molokhia M, Maconochie N, Patrick AL, Doyle P. Cross-sectional analysis of adverse outcomes in 1,029 pregnancies of AfroCaribbean women in Trinidad with and without systemic lupus erythematosus. Arthritis Res Ther 2007;9(6):R124.

3. Kaul A, Gordon C, Crow MK, Touma Z, Urowitz MB, van Vollenhoven R. Systemic lupus erythematosus. Nat Rev Dis Primers 2016;2:16039.

4. Airoldi J, Weinstein L. Clinical significance of proteinuria in pregnancy. Obstet Gynecol Surv 2007;62(2):117-124.

5. Zhang W, Chen SL. An overview on systemic lupus erythematosus pregnancy. Mod Rheumatol 2003;13(4):293-300.

6. Schreiber K, Lykke JA, Nielsen HS, Jacobsen S. Systemic lupus erythematosus and pregnancy. Ugeskrift for laeger 2016;178(31).

7. Moroni G, Doria A, Giglio E, Tani C, Zen M, Strigini F. Fetal outcome and recommendations of pregnancies in lupus nephritis in the 21 st century. A prospective multicenter study. J Autoimmun 2016;74:6-12.

8. Abheiden CN, Blomjous BS, Kroese SJ, Bultink IE, Fritsch-Stork RD, Lely AT. Lowmolecular-weight heparin and aspirin use in relation to pregnancy outcome in women with systemic lupus erythematosus and antiphospholipid syndrome: A cohort study. Hypertens Preǵnancy 2017;36(1):8-15.

9. Hochberg MC. Updating the American College of Rheumatology revised criteria for the classification of systemic lupus erythematosus. Arthritis Rheum 1997; 40(9):1725.

10. Romero-Diaz J, Isenberg D, Ramsey-Goldman R. Measures of adult systemic lupus erythematosus: updated version of British Isles Lupus Assessment Group (BILAG 2004), European Consensus Lupus Activity Measurements (ECLAM), Systemic Lupus Activity Measure, Revised (SLAM-R), Systemic Lupus Activity Questionnaire for Population Studies (SLAQ), Systemic Lupus Erythematosus Disease Activity Index 2000 (SLEDAI-2K), and Systemic Lupus International Collaborating Clinies/American College of Rheumatology Damage Index 
(SDI). Arthritis Care Res 2011;63 Suppl 11:S37-46.

11. Isenberg DA, Rahman A, Allen E, Farewell V, Akil M, Bruce IN. BILAG 2004. Development and initial validation of an updated version of the British Isles Lupus Assessment Group's disease activity index for patients with systemic lupus erythematosus. Rheumatology (Oxford, England) 2005;44(7):902-906.

12. Borchers AT, Naguwa SM, Keen CL, Gershwin ME. The implications of autoimmunity and pregnancy. $J$ Autoimmun 2010;34(3):J287-299.

13. Nicklin A, Byard RW. Lethal manifestations of systemic lupus erythematosus in a forensic context. J Forensic Sci 2011;56(2):423-428.

14. Cordeiro A, Lermann R, Ambrosio P, Nogueira I, Serrano F. Pregnancy and antiphospholipid antibodies in systemic lupus erithematosus patients: an outcome evaluation. Acta Reumatol Port 2009;34(3):486-491.

15. Tsangaris I, Tsaknis G, Anthi A, Orfanos SE. Pulmonary hypertension in parenchymal lung disease. Pulm Med 2012;2012:684781.

16. Lai M, You Z, Ma H, Lei L, Lu F, He D. Effects of shoutai pills on expression of Th1/Th2 eytokine in maternal-fetal interface and pregnancy outcome. Zhongguo Zhong yao za zhi $=$ China journal of Chinese materia medica 2010;35(22):3065-3068.

17. Saito $S$, Nakashima $A$, Shima T, Ito $M$. Th1/Th2/Th17 and regulatory T-cell paradigm in pregnancy. Am J Reprod Immunol 2010;63(6):601-610.

18. Jamin C, Achour A, Youinou P, Pers JO. Regulatory lymphocytes: a new cooperation between $\mathrm{T}$ and $\mathrm{B}$ cells for a better control of the immune response. Presse medicale (Paris, France: 1983) 2014;43(1):18-26.

19. Liu Q, Liu Z, Rozo CT, Hamed HA, Alem $\mathbf{F}$, Urban JF, Jr. The role of B cells in the development of CD4 effector T cells during a polarized Th2 immune respon- se. J Immunol (Baltimore, Md: 1950) $2007 ; 179(6): 3821-3830$.

20. Ruiz-Arruza I, Barbosa C, Ugarte A, Ruiz-Irastorza G. Comparison of high versus low-medium prednisone doses for the treatment of systemic lupus erythematosus patients with high activity at diagnosis. Autoimmun Rev 2015;14(10):875-879.

21. Ko HS, Ahn HY, Jang DG, Choi SK, Park YG, Park IY. Pregnancy outcomes and appropriate timing of pregnancy in 183 pregnancies in Korean patients with Sle. Int J Med Sei 2011;8(7):577-583.

22. Ma H, Luo M, Dai LL. Influences of surfactant and nanoparticle assembly on effective interfacial tensions. Phys Chem Chem Phys 2008;10(16):2207-2213.

23. El-Bastawissi AY, Sorensen TK, Akafomo CK, Frederick IO, Xiao R, Williams MA. History of fetal loss and other adverse pregnancy outcomes in relation to subsequent risk of preterm delivery. Matern Child Health J 2003;7(1):53-58.

24. Zhao C, Zhao J, Huang $Y$, Wang $Z$, Wang $H$, Zhang H. New-onset systemic lupus erythematosus during pregnancy. Clin Rheumatol 2013;32(6):815-822.

25. Kokeny G, Godo M, Nagy E, Kardos M, Kotsch K, Casalis P. Skin disease is prevented but nephritis is accelerated by multiple pregnancies in autoimmune MRL/LPR mice. Lupus 2007;16(7):465-477.

26. Bundhun PK, Soogund MZ, Huang F. Impact of systemic lupus erythematosus on maternal and fetal outcomes following pregnancy: A meta-analysis of studies published between years 2001-2016. J Autoimmun 2017;79:17-27.

27. Bundhun PK, Kumari A, Huang F. Differences in clinical features observed between childhood-onset versus adult-onset systemic lupus erythematosus: A systematic review and meta-analysis. Medicine (Baltimore) 2017;96(37):e8086. 